\title{
Проблемы применения аддитивных технологий для изготовления запасных деталей машин
}

\author{
Н.К. Толочко ${ }^{1}$, В.М. Синельников ${ }^{2}$, О.В. Сокол ${ }^{3}$ \\ Белорусский государственный аграрный технический университет \\ (2. Минск, Республика Беларусь) \\ e-mail: ${ }^{1}$ n.tolochko@hotmail.com, ${ }^{2}$ vsinelnikov@yahoo.com, ${ }^{3}$ oliaialo@gmail.com
}

\begin{abstract}
Аддитивные технологии могут эффрективно применяться для изготовления запчастей, необходимых для внеплановых ремонтов машин, вызванных их внезапными отказами, особенно если простои машин из-за отказов приводят к значительным производственным потерям. Однако до сих пор изготовление запчастей с помощью этих технологий не получило большого распространения, что обусловлено рядом проблем, анализу которых посвящена данная статья.

В статье выполнен обзор разных видов аддитивных технологий, рассмотрены особенности изготовления деталей машин из металлов и полимеров с их помощью. Обсуждены причины, сдерживающие широкое применение аддитивных технологий для изготовления запчастей, в том числе, высокая стоимость 3D-принтеров и строительных материалов, ограниченные функциональные возможности 3D-принтеров и ограниченный спектр строительных материалов. Описана методология оценки экономической эффективности приобретения запчастей, изготавливаемых с применением аддитивных технологий, основу которой составляет методика сравнительной оценки затрат, связанных с ремонтом, предполагающим приобретение запчастей, изготавливаемых по разным вариантам с помощью как аддитивных, так и традиционных технологий. По результатам этой оценки принимается решение о целесообразности применения аддитивных технологий для изготовления запчастей по одному из вариантов, для которого затраты, связанные с ремонтом, оказываются наименьшими. Рассмотрены частные случаи принятия такого решения - исходя из критериев минимизации покупной стоимости запчастей и минимизации длительности их изготовления. Первый случай имеет место, когда требуемая запчасть обычно поставляется не индивидуально, а в составе узла или в комплекте с другими запчастями, причем покупная стоимость узла или комплекта намного больше покупной стоимости отдельной запчасти, изготавливаемой с помощью аддитивных технологий; второй - когда длительность простоя, связанного с приобретением запчасти, изготавливаемой по обычным технологиям, намного больше длительности простоя, связанного с приобретением запчасти, изготавливаемой по аддитивным технологиям.
\end{abstract}

Ключевые слова: ремонт машин, запасные детали, аддитивные технологии, экономическая эфрфективность.

Введение. Эффрективность ремонта машин во многом зависит от уровня обеспеченности запчастями. Однако, как показывает анализ состояния современного ремонтного производства, при решении вопросов обеспечения запчастями нередко приходится сталкиваться со значительными трудностями [1]. Традиционно запчасти изготавливаются и поступают в продажу разными по размеру партиями, которые зачастую подлежат длительному хранению. Запчасти привязывают к себе значительную часть фринансовых средств, при этом довольно сложно предугадать, когда и сколько запчастей потребуется. Порой некоторые из них никогда не используются. Многие предприятия производят высоко кастомизированную продукцию, что еще больше увеличивает количество запчастей и, следовательно, усложняет управление запасами. Вполне возможно, что по мере ускорения технического прогресса запчасти, длительно хранящиеся на складе, уже не будут соответствовать эксплуатационным требованиям на тот момент, когда они понадобятся. Предприятия также нередко вынуждены проводить ремонт машин, которые уже настолько устарели, что запчасти для них больше не существуют. В таких случаях приходится изготавливать запчасти по индивидуальным заказам, что является дорогостоящим и длительным процессом, особенно если для их изготовления требуются специальные инструменты, пресс-фрормы, литейные фрормы и т.п.

Вопросы обеспечения запчастями становятся крайне острыми, когда необходимо проводить внеплановые ремонты машин, вызванные их отказами в работе. На сегодняшний день затраты на приобретение запчастей составляют $50-70 \%$ от стоимости ремонта [2], причем большинство последствий отказов машин устраняются благодаря использованию запчастей, например, у сельхозтехники они доходят до 70\% [3]. 
Отказы машин в работе связаны с внезапным выходом из строя деталей по непредвиденным причинам, таким как нарушение правил эксплуатации машин, несвоевременное или некачественное техническое обслуживание и ремонт машин, заводской брак, стихийные бедствия и др. Возникновению отказов машин способствуют сложные условия их эксплуатации. Так, на сельхозтехнику во время ее работы могут оказывать нежелательное влияние, повышающее вероятность ее отказов, погодно-климатические факторы (температура, влажность, запыленность воздуха, атмосферные осадки, солнечная радиация и др.); свойства почвы (плотность, влажность, содержание абразивных частиц, каменистость и др.); свойства растений (плотность, влажность, сопротивление резанию и транспортированию, способность прилипать к поверхности деталей и забивать рабочие органы и др.) [4].Кроме того, причиной большой вероятности отказов машин являются чрезмерно длительные сроки их эксплуатации, вследствие чего надежность машин снижается. Так, в России доля используемых сельхозмашин с вышедшими нормативными сроками эксплуатации, т.е. старше 10 лет, достигает 70\% [5].

Особенно актуальным является сокращение сроков обеспечения запчастями, требуемыми для внеплановых ремонтов, когда простои внезапно отказавших машин могут вызвать большие производственные потери. Так, простой сельхозтехники в результате поломки на поле в период уборочных работ вызывает потери пшеницы 26,6 кг/га в день, а ее простой на животноводческой ферме вызывает снижение удоя коров из-за несвоевременного кормления на 5-8\% [6].

Если нужные для внеплановых ремонтов запчасти отсутствуют на складе, то их, как правило, приходится приобретать на стороне, поскольку далеко не каждое предприятие, осуществляющее ремонт, имеет возможности изготавливать запчасти собственными силами, особенно если они отличаются конструктивной сложностью. Однако нередко стоимость запчастей, изготавливаемых по традиционным технологиям, оказывается высокой, а сроки их изготовления - длительными. В таких случаях может оказаться весьма эффективным изготовление запчастей с помощью аддитивных технологий (АМ-технологий от англ. Additive Manufacturing), или технологий 3D-печати, согласно которым изделия создаются путем послойного построения непосредственно по компьютерным моделям.

Применение АМ-технологий позволяет сократить расходы на внеплановые ремонты машин, связанные приобретением запчастей, исключить вероятность сверхнормативного простоя машин в ремонте из-за нехватки запчастей и ускорить выпуск машин с неплановых ремонтов, упростить инфраструктуру материально-технического обеспечения ремонтного производства. Предприятия, осуществляющие ремонт, могут за счет применения АМ-технологий создавать собственные склады запчастей или пользоваться услугами специализированных фрирм, изготавливающих детали на основе АМтехнологий. При этом для получения требуемой детали достаточно переслать ее электронную 3D-модель в одну из таких фрирм. B результате упрощается логистика и сокращается время поставки запчастей, ускоряется ремонт и уменьшаются объемы складских запасов. Таким образом, применение АМ-технологий в ремонтном производстве может привести к кардинальному изменению принципов организации всей работы ремонтных предприятий [1].

Однако до сих пор изготовление запчастей с помощью АМ-технологий не получило широкого распространения $[1,5,7]$. Это обусловлено рядом проблем, краткому анализу которых посвящена данная статья.

Особенности применения АМ-технологий. Существует два основных направления применения АМ-технологий для изготовления деталей машин: 1) изготовление прототипов деталей, т.е. их демонстрационных или экспериментальных образцов в целях повышения эффективности процессов проектирования машин и 2) изготовление собственно деталей в целях повышения эффективности процессов производства или ремонта машин (в последнем случае речь идет об изготовлении запчастей).

Изготовление запчастей с помощью АМтехнологий может осуществляться как на предприятиях, производящих машины, таки на предприятиях, выполняющих ремонт машин, при условии, что эти предприятия имеют необходимое AM-оборудование, т.е. 3D-принтеры. При этом ремонт машин может проводиться как на ремонтных предприятиях, так и в ремонтных подразделениях предприятий, эксплуатирующих машины. Кроме того, запчасти могут изготавливаться на специализированных предприятиях, занимающихся аддитивным производством и оказывающих услуги другим предприятиям по изготовлению различных деталей, в том числе запчастей, с помощью АМ-технологий.

Известны разнообразные виды АМтехнологий, различающиеся принципами послойного построения деталей, и, соответственно, разнообразные типы3D-принтеров, различающиеся принципами конструктивного исполнения. В свою очередь, 3D-принтеры каждого типа могут иметь многочисленные фирменные модели, различающиеся техническими характеристиками.
ISSN 2311-1828

http://enm.khntusg.com.ua
Інженерія природокористування, 2019, №3(13), с. 92 - 101 Engineering of nature management, 2019, \#3(13), p. 92 - 101 
АМ-технологии позволяют создавать детали из самых разных материалов. Большинство деталей машин являются металлическими, в меньшей мере в машинах используются полимерные детали, доля которых, однако, постоянно растет. Поэтому особый практический интерес представляют такие АМ-технологии, которые позволяют создавать детали из металлов, а также из полимеров.

Изготовление деталей с помощью АМтехнологий может быть прямым и непрямым. В первом случае готовые детали получают непосредственно с помощью АМ-технологий, во втором - сначала с помощью АМ-технологий создают формообразующую оснастку, которую затем используют для получения деталей обычными способами. Прямым путем можно получать как металлические, так и полимерные детали. Непрямой путь применяется для получения металлических деталей, которые технически трудно или экономически невыгодно получать прямым путем.

Ниже приводятся примеры прямого и непрямого изготовления деталей с применением некоторых, наиболее распространенных видов АМтехнологий [8-10].

Прямое изготовление деталей из металлов осуществляется с помощью технологий Selective Laser Melting (SLM) и Electron Beam Melting (EBM), согласно которым их построение идет путем послойного нанесения металлического порошка на рабочую платформу и его селективного сплавления лазерным или электронным лучом. Также прямое изготовление деталей из металлов происходит путем подачи металлического порошка или проволоки непосредственно к месту построения, где послойно проводится лазерная наплавка - технологии Laser Engineered Net Shape (LENS) (порошок) и Laser Metal Deposition (LMD) (порошок или проволока) либо электронно-лучевая наварка - технология Electron Beam Direct Manufacturing (EBDM) (проволока). Прямое изготовление деталей из полимеров осуществляется с помощью технологии Fused Deposition Modeling (FDM) - путем послойной укладки волокна из термопластичного полимера, нагретого до полужидкого состояния, с последующим затвердеванием уложенных слоев. Кроме того, для прямого изготовления деталей и из металлов, и из полимеров применяется технология Sheet Lamination (SL), согласно которой построение деталей происходит путем пакетирования и соединения между собой контурных листовых выкроек из металлических или полимерных0 материалов.

Непрямое изготовление деталей с помощью АМ-технологий в основном связано с применением этих технологий для создания формообразующей литейной оснастки, в частности, выжигае- мых и выплавляемых моделей, а также литейных форм. Выжигаемые модели получают из полистирола по технологии Selective Laser Sintering (SLS) - путем послойного нанесения полимерного порошка на рабочую платформу и его селективного спекания лазерным лучом, из полиметилметакрилата по технологии Multi-Jet Modeling (MJM) - путем капельной подачи полимера непосредственно в место построения, где он затем затвердевает, или из фотополимеров по технологии Stereolithography Apparatus (SLA) - путем последовательного формированиях слоев жидкого фотополимера и их селективного затвердевания под действием луча ультрафиолетового лазера. Выплавляемые модели получают из литьевого воска с фротополимерным связующим по МJM-технологии, а также из ПВХ-пленок по SL-технологии. Литейные фрормы получают с помощью SLSтехнологии из литейного песка с полимерным связующим или с помощью Ink-Jet-технологии, когда связующее подается каплями на последовательно формируемые слои песка или гипса.

Таким образом, имеются широкие возможности изготовления различных деталей машин, в том числе запчастей, с помощью АМ-технологий, эфффективность которого может быть различной - в зависимости от того, какие виды АМтехнологий, а также какие модели 3D-принтеров соответствующих типов используются. Поэтому при решении вопросов об изготовлении запчастей с помощью АМ-технологий важно знать достоинства и недостатки разных видов АМтехнологий и уметь выбирать те из них, применение которых будет наиболее эфффективным.

Факторы эффективности АМ-технологий. Эффрективность применения АМ-технологий для изготовления запчастей зависит от того, насколько качественно и своевременно они могут быть изготовлены при условии обеспечения минимальных затрат, связанных с ремонтом машин. В этой связи представляет особый интерес рассмотрение факторов, способных оказывать как положительное, так и отрицательное влияние на эффективность применения АМ-технологий для изготовления различных деталей.

Изготовление деталей с помощью АМтехнологий будет тем эффективней, чем лучше будут технические характеристики 3D-принтеров и свойства строительных материалов, которыми определяются качество, скорость и стоимость изготовления деталей. Распространение АМтехнологий в сфере производства деталей будет тем значительнее, чем больше будет разнообразие выпускаемых моделей 3D-принтеров и строительных материалов.

Наиболее важными техническими характеристиками 3D-принтеров, влияющими на качество изготавливаемых деталей, являются 
максимальные размеры зоны построения и точность построения.

Увеличение максимальных размеров зоны построения открывает возможности для изготовления более крупных деталей в рамках единого процесса 3D-печати, но вместе с тем оно ведет к повышению стоимости3D-принтеров, которая для многих из них является весьма высокой даже в тех случаях, когда эти размеры сравнительно малы. Например, большинство 3D-принтеровSLM-, LENS- и SLA-типов стоят более 500 тыс. долл. США, а некоторые из них, имеющие значительные максимальные размеры зоны построения, - более 1 млн. долл. США (табл. 1).

Таблица 1. Максимальные размеры зоны построения и стоимость разных3D-принтеров [8-13]

\begin{tabular}{|c|c|c|c|c|}
\hline 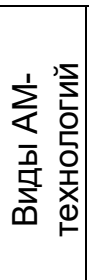 & 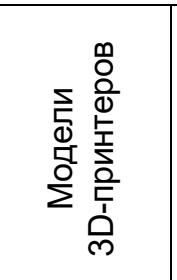 &  & 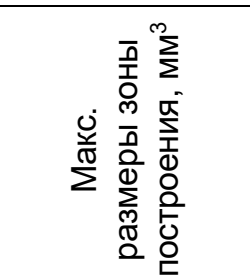 & 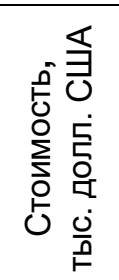 \\
\hline \multirow{3}{*}{$\sum_{\omega}$} & SLM125 & \multirow{3}{*}{ 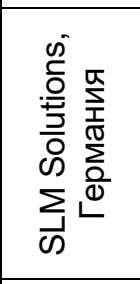 } & $120 \times 120 \times 75$ & $\begin{array}{l}400- \\
500\end{array}$ \\
\hline & SLM 280 & & $280 \times 280 \times 350$ & $\begin{array}{l}750- \\
1000\end{array}$ \\
\hline & SLM 500 & & $500 \times 280 \times 325$ & $\begin{array}{l}1000- \\
2000\end{array}$ \\
\hline \multirow{2}{*}{ 邑 } & LENS 450 & \multirow{2}{*}{ 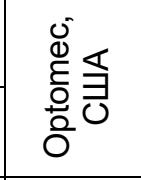 } & $100 \times 100 \times 100$ & $\sim 300$ \\
\hline & $\begin{array}{l}\text { LENS } \\
850-R\end{array}$ & & $900 \times 1500 \times 900$ & $\sim 1200$ \\
\hline \multirow{2}{*}{ ๘ } & iPro 8000 & \multirow{2}{*}{ 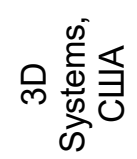 } & $650 \times 750 \times 550$ & $\sim 700$ \\
\hline & ProX 950 & & $1500 \times 750 \times 550$ & $\sim 1300$ \\
\hline
\end{tabular}

Точность построения существенно зависит от шага построения, т.е. от толщины последовательно формируемых слоев строительного материала: чем меньше толщина слоев, тем выше точность построения. Но с уменьшением толщины слоев увеличивается их общее количество, необходимое для изготовления детали, что ведет к увеличению длительности и, в конечном счете, стоимости изготовления. К тому же следует иметь в виду, что возможности уменьшения толщины слоев ограничены: для 3D-принтеровкаждоготипасуществуютопределенные минимальные толщины слоев, которые могут быть достигнуты с учетом свойств используемых строительных материалов и механизмов формирования из них слоев.
Расширение спектра строительных материалов создает предпосылки для улучшения функциональных свойств изготавливаемых деталей. Каждый тип 3D-принтеров предназначен для работы с определенными строительными материалами. Обычно строительные материалы поставляются фрирмами-производителями 3D-принтеров вместе с выпускаемыми ими принтерами, в которых эти материалы используются. Однако количество этих материалов весьма ограничено, несмотря на то, что 3D-принтеры в принципе можно настроить на работу с их более широким спектром. Как правило, каждая фрирма предлагает несколько марок материалов для 3D-принтера определенного типа, который она выпускает. При этом разные фирмы предлагают для выпускаемых ими 3D-принтеров одного и того же типа почти одинаковый по составу набор строительных материалов (табл. 2).

Таблица 2. Металлические порошки, поставляемые разными фирмами-производителями 3Dпринтеров для прямого изготовления деталей из металлов [8-10,12-15]

\begin{tabular}{|c|c|c|c|c|c|c|}
\hline $\begin{array}{c}\text { Фирмы- } \\
\text { производители }\end{array}$ & 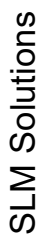 & ભ & $\begin{array}{l}0 \\
\stackrel{1}{\varepsilon} \\
\frac{0}{0} \\
\text { Oे }\end{array}$ & 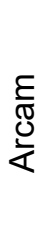 & $\begin{array}{l}\text { D } \\
\frac{c}{\Phi} \\
\frac{D}{\infty} \\
\text { क } \\
0\end{array}$ &  \\
\hline $\begin{array}{l}\text { Нержавеющие } \\
\text { стали }\end{array}$ & + & + & + & & + & + \\
\hline $\begin{array}{l}\text { Инструменталь- } \\
\text { ные стали }\end{array}$ & + & + & & & & + \\
\hline $\begin{array}{l}\text { Мартенситно- } \\
\text { стареющие } \\
\text { стали }\end{array}$ & & & & & + & + \\
\hline Ті / Ті-сплавы & + & + & + & + & & + \\
\hline Al / Al-сплавы & + & + & & & & + \\
\hline $\begin{array}{l}\text { Сплавы Инко- } \\
\text { нель }\end{array}$ & + & + & + & + & & + \\
\hline Co-Cr-сплавы & + & + & & & + & + \\
\hline
\end{tabular}

Следует заметить, что, как правило, к строительным материалам предъявляются специальные требования не только по составу, но и по некоторым другим характеристикам. Например, металлические порошки для 3D-печати должны coстоять из особых по размерам и форме частиц. Это означает, что строительные материалы, поставляемые какой-либо фрормой для работы выпускаемых ею 3D-принтеров, далеко не всегда подходят для работы 3D-принтеров такого же типа, выпускаемых другими фирмами. 
Многие строительные материалы стоят довольно дорого. Например, в 3D-принтерах для прямого изготовления деталей из металлов используются металлические порошки, стоимость которых составляет (в долл. США на 1 кг порошка): для нержавеющих сталей - 300, для сплавов Инконель - 400, для титановых сплавов - 500. Стоимость металлической проволоки, используемой в 3D-принтерах такого типа, также довольно высока, она приблизительно лишь в 1,5 раза меньше стоимости соответствующего металлического порошка.

Таким образом, существуют различные факторы, способные оказывать влияние на эфффективность применения АМ-технологий для изготовления различных деталей машин, включая запчасти. Распространению АМ-технологий способствует совершенствование 3D-принтерови строительных материалов. Главной причиной, сдерживающей широкое применение АМтехнологий, является высокая стоимость большинства типов 3D-принтеров, а также многих строительных материалов. Поэтому при принятии решений об изготовлении запчастей с помощью АМ-технологий следует исходить, прежде всего, из соображений экономической целесообразности применения АМ-технологий.

Высокая стоимость 3D-принтеров сдерживает их применение на производственных предприятиях, поскольку многие из них не могут позволить себе приобретение оборудования, стоимость которого исчисляется сотнями тысяч долл. США, а сроки окупаемости могут быть довольно длительными. С другой стороны, высокая стоимость 3D-принтеров, а также строительных материалов отражаются на стоимости производимых запчастей, спрос на которые ограничен из-за их высокой цены.

Оценка экономической эффрективности применения АМ-технологий. Среди проблем, из-за которых сдерживается широкое применение АМ-технологий для изготовления запчастей, есть одна, особая проблема, заключающаяся в том, что работники многих предприятий, эксплуатирующих машины, не имеют достаточных знаний об АМ-технологиях, и, самое главное, не владеют методологией оценки эффективности их применения для изготовления запчастей, необходимых для внеплановых ремонтов машин. Осуществить такую оценку, вообще говоря, довольно сложно, поскольку для этого следует проводить сравнительный анализ довольно большого числа разных видов АМ-технологий и, соответственно, разных типов 3D-принтеров, различающихся конструктивными схемами, техническими характеристиками, используемыми строительными материалами. При этом также следует учитывать, что 3D-принтеры одного и того же типа могут иметь разные конструктивные варианты (фирменные модели).

В последние годы, с целью содействия распространению АМ-технологий, консалтинговые компании в ряде индустриально развитых стран, специализирующиеся в сфере инновационного менеджмента, начали консультировать различные предприятия по вопросам применения этих технологий; вместе с тем фрирмы, производящие АМ-оборудование, начали открывать собственные консалтинговые подразделения [16]. Как правило, в этих методологиях уделяется внимание частным аспектам применения этих технологий: оценке экономических перспектив их применения [17], анализу организационных, технических, сбытовых и других фракторов, стимулирующих их применение [18], подбору изделий, пригодных для изготовления с их применением [19], определению стоимости изготовления изделий с их применением [20]. Все они в обобщенном виде представлены в методологии оценки целесообразности применения аддитивных технологий, основу которой составляет алгоритм информационно-аналитических мероприятий, включающий ознакомление с этими технологиями, определение возможностей изготовления изделий с их применением и анализ экономических последствий их применения [16].

Все эти методологии предусматривают две основные организационно-методические формы содействия предприятиям в освоении АМтехнологий[16]: 1) проведение учебных семинаров по вопросам примененияэтих технологий (например, EOS Consulting (Германия) регулярно проводит трехдневные семинары по данным вопросам с участием представителей предприятий); 2) разработка рекомендаций по выбору этих технологий с учетом результатов специально проводимых аналитических исследований (например, Berenschot Consulting (Дания) осуществляет разработку моделей аддитивного производства на основе анализа рынка этих технологий и технико-экономического обоснования их применения на предприятиях). Недостаток первой формы: участники семинаров получают поверхностные знания, недостаточные для принятия правильных решений по выбору этих технологий; недостаток второй формы: длительная разработка рекомендаций по выбору этих технологий (например, Berenschot Consulting разрабатывает модели аддитивного производства в течение 16 недель). В этой связи указывается на целесообразность реализации таких методологий на основе использования системы поддержки принятия решений (СППР) [16].

Также следует подчеркнуть, что все эти методологии предполагают применение АМтехнологий на промышленных предприятиях, 
производящих изделия и планирующих создание новых производств на основе применении этих технологий. Вместе с тем имеется большое число предприятий, у которых нет необходимости в производственном освоении АМтехнологий, так как у них в силу специфики их деятельности не предусмотрен выпуск промышленных изделий. К ним относятся сельскохозяйственные, транспортные, мелиоративные, лесозаготовительные, дорожно-строительные и другие предприятия, имеющие в своем распоряжении большой парк эксплуатируемых машин, для внепланового ремонта которых приходится приобретать запасные детали, в том числе путем их изготовления на стороне с применением АMтехнологий. При этом руководители таких предприятий должны иметь аргументированные основания для принятия соответствующих решений по приобретению запасных деталей, изготавливаемых с применением этих технологий.

Ниже рассматривается методология оценки экономической эффрективности применения АМтехнологий для изготовления запчастей для внепланового ремонта машин. Она предназначена к непосредственному пользованию предприятиями, эксплуатирующими различные машин и нуждающимися в обеспечении запчастями их внепланового ремонта. Основные ее положения изложены в работе [21].

Согласно рассматриваемой методологии предусматривается следующий алгоритм информационно-аналитических мероприятий: 1) определение принципиальных возможностей изготовления запчастейс применением АМ-технологий; 2) определение возможных видов АМтехнологий, позволяющих изготовить запчасти требуемого качества, в том числе в сочетании с традиционными технологиями (Т-технологиями); 3) определение возможных предприятий-изготовителей запчастей; 4) определение возможных способов доставки изготовленных запчастей; определение затрат, связанных с внеплановым ремонтом машин, для разных вариантов изготовления запчастей(для разных видов применяемых АМ-технологий и/или Т-технологий, а также для разных предприятий-изготовителей и способов доставки запчастей).

Для конкретных случаев внепланового ремонта решения о целесообразности применения АМ-технологий для изготовления запчастей по одному из возможных вариантов изготовления принимаются по результатам сравнительной оценки затрат, связанных с ремонтом, а именно: выбирается тот вариант изготовления, для которого затраты предприятия, осуществляющего ремонт, оказываются наименьшими.

В общем случае решение о применении АМтехнологий для изготовления запчастей прини- мается при условии

$$
3_{\text {PAM }}<3_{\text {PT }}
$$

где $3_{\text {РАм }}$ и $3_{\text {Рт }}$ - общие затраты, связанные с ремонтом, заключающимся в замене неисправной детали на запчасть, изготовленную с применением АМ-технологии (АМ-запчасть) или Т-технологии (Т-запчасть),

$$
\begin{gathered}
3_{\mathrm{PAM}}=\mathrm{C}_{\mathrm{AM}}+Д_{\text {АМ }(t)} t_{\text {ДАМ }}+ \\
+\Pi_{(t)}\left(t_{\mathrm{PAM}}+t_{\text {ИАМ }}+t_{\text {ДАМ }}\right)+\mathrm{P} \\
3_{\mathrm{PAM}}=\mathrm{C}_{\mathrm{T}}+Д_{\mathrm{T}(t)} t_{\text {ДТ }}+\Pi_{(t)}\left(t_{\mathrm{PT}}+t_{\text {ИТ }}+t_{\text {ДАМ }}\right)+\mathrm{P}
\end{gathered}
$$

где $\mathrm{C}_{\mathrm{Am}}$ и $\mathrm{C}_{\mathrm{T}}$ - покупная стоимость запчасти, Д $_{(t)}$ - затраты по доставке запчасти в единицу времени, $\Pi_{(t)}$ - ущерб из-за простоя в единицу времени, включая расходы, понесенные из-за простоя, и доходы, неполученные из-за простоя, $t_{\mathrm{P}}-$ длительность ремонтных работ, $t_{\text {ИАм }}$ и $t_{\text {ИТ }}-$ длительность изготовления запчасти $t_{\text {дАм }}$ и $t_{\text {дт }}$ длительность доставки запчасти Р - затраты на ремонтные работы по замене неисправной детали на запчасть.

Предполагается, что значения $Д_{(t)}, \Pi_{(t)}, t_{\mathrm{P}}$ и $\mathrm{P}$ $P$ одинаковы как для АМ-запчасти, так и для Тзапчасти. С учетом этих предположений выражение (1) в развернутом виде можно представить следующим образом:

$$
\begin{gathered}
\mathrm{C}_{\mathrm{AМ}}+Д_{(t)} t_{\text {ДАМ }}+\Pi_{(t)}\left(t_{\text {ИАМ }}+t_{\text {ДАМ }}\right)< \\
<\mathrm{C}_{\mathrm{T}}+\text { Д }_{\mathrm{T}(t)} t_{\text {ДТ }}+\Pi_{(t)}\left(t_{\text {ИТ }}+t_{\text {ДАМ }}\right)
\end{gathered}
$$

В отдельных случаях возможны упрощенные условия принятия решения о применении АМтехнологий для изготовления запчастей. Ниже рассмотрены два наиболее характерных случая.

Случай 1 . Т-запчасть поставляется не индивидуально, а в составе узла или в комплекте с другими запчастями, причем покупная стоимость узла или комплекта намного больше, чем отдельной АМ-запчасти. Если при этом значения Д(t) и $\Pi_{(\mathrm{t})}$ малы, то основанием для принятия решения о применении АМ-технологий для изготовления запчастей будет выполнение условия

$$
\mathrm{C}_{\mathrm{AM}} \ll \mathrm{C}_{T \Sigma},
$$

где $\mathrm{C}_{T \Sigma}$ - покупная стоимость узла или комплекта, содержащего Т-запчасть.

Случай 2. Длительность приобретения Т-запчасти намного больше, чем АМ-запчасти и, соответственно, длительность простоя, связанного с приобретением Т-запчасти, намного больше, чем длительность простоя, связанного с приобретением АМ-запчасти. Если при этом значение $\Pi_{(\mathrm{t})}$ велико, то основанием для принятия решения 
о применении АМ-технологий для изготовления запчастей будет выполнение условия

$$
t_{\Pi \mathrm{MM}} \ll t_{\Pi \mathrm{T}},
$$

где $t_{\text {Пам }}$ и $t_{\text {Пт }}$ - длительности приобретения запчастей $\left(t_{\text {ПАМ }}=t_{\text {ИАМ }}+t_{\text {ДАМ }}\right.$ и $\left.t_{\text {ПТ }}=t_{\text {ИТ }}+t_{\text {ДТ }}\right)$.

Очевидно, что условие (4) будет выполнятьСя, если $t_{\text {ИАМ }} \ll t_{\text {ИТ }}$ и/или $t_{\text {ДАМ }} \ll t_{\text {дт }}$. Соотношение $t_{\text {ИАм }} \ll t_{\text {Ит }}$ свидетельствует о том, что АМтехнологии по производительности намного превосходят традиционные технологии изготовления деталей, что действительно имеет место в производственно практике. В свою очередь, соотношение $t_{\text {Дам }} \ll t_{\text {дт }}$ свидетельствует о недостаточно развитой инфраструктуре снабжения Тзапчастями, а также о большой удаленности предприятий-изготовителей Т-запчастей.

Условие (4) означает, что ущерб из-за простоя, связанного с длительным приобретением Т-запчасти, т.е. значение $\Pi_{(t)}\left(t_{\text {ит }}+t_{\text {дАм }}\right)$, оказывается настолько большим, что по сравнению с ним затраты на приобретение АМ-запчасти уже не играют сколь бы то ни было существенной роли и главной задачей становится как можно скорее изготовить АМ-запчасть и доставить ее к месту ремонта.

Правильность и быстрота принятия решений о применении AM-технологий для изготовления запчастей согласно рассматриваемой методологии могут быть обеспечены использованием СППР. Обычно разработка СППР включает разработку ее структурной схемы и алгоритма функционирования, информационного, математического и программного обеспечения.

Как показывает практика, наиболее трудоемкой является разработка информационного обеспечения, в частности, подготовка информационных материалов для составления базы данных, включая сведения о запчастях, которые наиболее вероятно могут быть использованы для внеплановых ремонтов машин и вместе с тем могут быть пригодны для изготовления с применением АМ-технологий, а также сведения об АМ-технологиях и (для сравнения) традиционных технологиях, которые могут применяться для изготовления запчастей. Подготовку информационных материалов можно проводить разными способами: путем прямого взаимодействия с предприятиями, как потребляющими запчасти, так и производящими их; на основе анализа информационных источников, в том числе таких как: производственные отчеты по ремонтным подразделениям, отчеты о движении материалов по складу, дефектные ведомости, ремонтная документация (подготовка сведений о запчастях); конструкторская документация на детали (отбор деталей, пригодных для изготовле- ния с применением аддитивных технологий); рекламная и производственно-техническая информация предприятий, работающих в сфере аддитивного производства (подготовка сведений об АМ-технологиях).

\section{Выводы}

1. Проанализированы особенности влияния различных фракторов на эфффективность применения аддитивных технологий для изготовления запасных деталей машин.

2. Рассмотрена методология оценки экономической эффективности применения аддитивных технологий для изготовления запасных деталей для внепланового ремонта машин.

\section{Литература}

1. Salmi M. Digital Spare Parts / M. Salmi [et al.] / Aalto University \& VTT Technical Research Centre of Finland Ltd., Finland, 2018. - 65 pp.

2. Чеботарёв М.И. Проблемы и перспективы развития технического сервиса в АПК / М.И. Чеботарёв, И.Г. Савин // Науч. ж. КубГАУ. - 2014. - №97. - С. 1-10.

3. Королькова Л.И. Методы расчета показателей надежности сельскохозяйственной техники, производственных процессов ее ремонта и прогнозирование запасов. Дис. ... док.технаук: 05.20.03. - Челябинск, 2003. - 372 с.

4. Новиков А.В. Диагностика и техническое обслуживание машин для сельского хозяйства: учеб. пособие / А.В. Новиков, И.Н. Шило, В.Н. Кецко [и др.]; под ред. Л.В. Новикова. - Минск: БГАТУ, 2010. - 404 с.

5. Федоренко В.Ф. Перспективы применения аддитивных технологий при производстве и техническом сервисе сельскохозяйственной техники: науч. аналит. Обзор / В.Ф.Федоренко, И.Г. Голубев. - М.: ФГБНУ «Росинформагротех», 2018. - 140 c.

6. Белайц Д.С. Механизм trade-in в сокращении времени простоев сельскохозяйственной техники / Д.С. Белайц //Вестник НГАУ. - 2018. - № 1. - С. 150-158.

7. Серебреницкий П.П. Аддитивные технологии в ремонтном производстве / П.П. Серебреницкий, А.С. Тетенькин // Аддитивные технологии. - 2017.- № 4. С. - 52-53.

8. Зленко М.А. Аддитивные технологии в машиностроении: пособие для инженеров. / М.А. Зленко, М.В. Нагайцев, В.М. Довбыш. - М.: ГНЦ РФ ФГУП «НАМИ», 2015.- 220 с.

9. Валетов В.А. Аддитивные технологии (состояние и перспективы): учебн. пособие. - СПб.: Университет ИТМО, 2015. - 63с.

10. Шкуро A.E. Технологии и материалы 3Dпечати: учеб.пособие / А.Е. Шкуро, П.С. Кривоногов. - Екатеринбург: Урал.гос. лесотехн. ун-т, 2017. - 99 c. 
11. Stevenson K. A Look Inside SLM Solutions' New 3D Metal Printers / K. Stevenson. - 2017. [Электронный ресурс] - Режим доступа: https: //www. fabbaloo. com/blog/2017/6/2/a-look-inside-sl m-solutions-new-3d-metal-printers. - Дата обращения: 18.10. 2019.

12. 3D принтер SLM 125. - 2019. [Электронный ресурс] - Режим доступа: https://top3dshop.r u/kupit-3d-printer/slm-125-hl.html. - Дата обращения: 16.10. 2019.

13. Berman N. The Five Most Expensive 3D Printers on the Market Today / N. Berman.- 2019. [Электронный ресурс] - Режим доступа: https://m oneyinc.com/the-five-most-expensive-3d-printers-o n-the-market-today/. - Дата обращения: 17.10.2019.

14. Metal Sintering Meets Industrial Needs with the EOS M 290. - 2014. [Электронныйресурс] - Peжимдоступа: https://www.engineering.com/DesignerEdge /DesignerEdgeArticles/ArticleID/7829/MetalSintering -Meets -Industrial-Needs-with-the-EOS-M290.aspx.- Дата обращения: 16.10. 2019.

15. Maxey K. Arcam's Q10 EBM Printer Answers the Need for Customized Metal Implants / K. Maxey. - 2015. [Электронныйресурс] - Режимдоступа: https://www.engineering.com/3DPrinting/3 DPrintingArticles/ArticleID/10319/Arcams-Q10-EBM -Printer -Answers -the -Need-for-Customized-MetalImplants.aspx.- Датаобращения: 17.10. 2019.

16. Van der Haar W. Assessing the appropriateness of additive manufacturing / W. van der Haar. Master thesis. University of Twente, Enschede, Netherlands, 2016. - 114 pp.

17. Weller C. Economic Perspectives on 3D Printing / C. Weller. Doc. dissertation. Techn. University of Aachen, Germany. 2015. - 234 pp.

18. Mellor S. Additive manufacturing: A framework for implementation / S. Mellor, L. Hao, D. Zhang // Int. J. Production Economics. - 2014. - Vol. 149. - P. 194-201.

19. Lindemann C. Towards a sustainable and economic selection of part candidates for additive manufacturing / C. Lindemann, T. Reiher, U. Jahnke, R. Koch // Rapid Prototyping J. - 2015. - № 21(2). - P. 216-227.

20. Baumers M. Economic aspects of additive manufacturing: benefits, costs and energy consumption / M. Baumers. Doc. thesis. Loughborough University, UK. 2012. - 266 pp.

21. Толочко Н.К. Методологические аспекты оценки целесообразности применения аддитивных технологий для изготовления запасных деталей машин / Н.К. Толочко, В.М. Синельников, О.В. Сокол [и др.] // Агропанорама. - 2018. - №2. - C. $37-41$.

\section{Reference}

1. Salmi, M. (2018) Digital Spare Parts. Aalto University \& VTT Technical Research Centre of Finland Ltd., Finland. 65 pp.

2. Chebotarev, M. I. and Savin, I. G. (2014) 'Problemy i perspektivy razvitiya tehnicheskogo servisa $\mathrm{V}$ APK', Nauchyj zhurnal KubGAU, (97), pp. 1-10. Available at: http://ej.kubagro.ru/2014/03/pdf/67.pdf.

3. Korol'kova, L. (2003). Metody rascheta pokazateley nadezhnosti sel'skohozyaystvennoy tehniki, proizvodstvennyh processov ee remonta i prognozirovanie zapasov. Doctor of Engineering. Chelyabinsk.

4. Novikov, A. V. et al. (2010) Diagnostika i thenicheskoe obsluzhivanie mashin dlya sel'skogo hozyaystva: ucheb.posobie. Minsk: BGATU, p. 404.

5. Fedorenko, V. F. and Golubev, I. G. (2018) Perspektivy primeneniya additivnyh tehnologiy pri proizvodstve i tehnicheskom servise sel'skohozyaystvennoy tehniki. Moscow: FGBNU «Rosinformagroteh», p. 140.

6. Belayc, D. S. (2018) 'Mehanizm trade-in v sokraschenii vremeni prostoev sel'skohozyaystvennoy tehniki', Vestnik NGAU, (1), pp. 150-158.

7. Serebrenickiy, P.P. and Teten'kin, A.S. (2017) Additivnye tehnologii $v$ remontnom proizvodstve, Additivnye tehnologii. (4), pp. 52-53

8. Zlenko, M. A., Nagaycev, M. V. and Dovbysh, V. M. (2015) Additivnye tehnologii v mashinostroenii: posobie dlya inzhenerov. Moscow: GNC RF FGUP «NAMl», p. 220

9. Valetov, V. (2015). Additivnye tehnologii (sostoyanie i perspektivy): uchebnoe posobie. SPb.: Universitet ITMO, p.63.

10. Shkuro, A.E. and Krivonogov, P.S. (2017) Tehnologii i materialy 3D-pechati: uchebnoe posobie. Ekaterinburg: UGLTU, p 99.

11. Stevenson, K. A. (2017) Look Inside SLM Solutions' New 3D Metal Printers. Available at: https: // www. fabbaloo. Com /blog /2017/6/2/a-look-insideslm-solutions-new-3d-metal-printers (Accessed: 18 October 2019).

12. Metal Sintering Meets Industrial Needs with the EOS M 290 (2014). Available at: https://www.engineering.com/DesignerEdge/DesignerEdgeArticles /ArticleID /7829/Metal -Sintering -Meets -IndustrialNeeds-with-the-EOS-M-290.aspx (Accessed: 16 October 2019).

13. Berman, N. (2019) The Five Most Expensive $3 D$ Printers on the Market Today. Available at: https: // moneyinc.com/the-five-most-expensive-3d-printer s-on-the-market-today/ (Accessed: 17 October 2019).

14. Metal Sintering Meets Industrial Needs with the EOS M 290 (2014). Available at: https://www.engineering. Com /DesignerEdge/DesignerEdgeArticle s/ArticleID /7829/Metal-Sintering-Meets-Industrial-N eeds-with-the-EOS-M-290.aspx (Accessed: 16 October 2019).
ISSN 2311-1828

http://enm.khntusg.com.ua
Інженерія природокористування, 2019, №3(13), с. 92 - 101 Engineering of nature management, 2019, \#3(13), p. 92 - 101 
15. Berman, N. (2019) The Five Most Expensive 3D Printers on the Market Today. Available at: https: // moneyinc. com /the-five-most-expensive-3d-printerson-the-market-today/ (Accessed: 17 October 2019).

16. Van der Haar, W. (2016) Assessing the appropriateness of additive manufacturing: Development of a knowledge based assessment methodology to determine appropriateness of additive manufacturing for an organisation. University of Twente, Enschede, Netherlands. Available at: http://essay.utwente.nl/71518/, p. 114.

17. Weller, C. (2016). Economic Perspectives on 3D Printing. Doctor of Economics and Social Sciences. Rheinisch-Westfälische Technische University of Aachen, p. 234.
18. Mellor, S., Hao, L. and Zhang, D. (2014) 'Additive manufacturing: A framework for implemen-tation', Int. J. Production Economics, 149, pp. 194-201.

19. Lindemann, C. et al. (2015) 'Towards a sustainable and economic selection of part candidates for additive manufacturing', Rapid Prototyping J., (21(2)), pp. 216-227.

20. Baumers, M. (2012) Economic aspects of additive manufacturing: benefits, costs and energy consumption. Loughborough University, UK, p. 266.

21. Tolochko, N. K., Sinelnikov, V. M. and Sokol, O. V. (2018) 'Metodologicheskie aspekty ocenki celesoobraznosti primeneniya additivnyh tehnologiy dlya izgotovleniya zapasnyh detaley mashin', Agropanorama, (2), pp. 37-41.

Анотація

\title{
Проблеми застосування адитивних технологій для виготовлення запасних деталей машин
}

\author{
М.К. Толочко, В.М. Синельников, О.В. Сокол
}

Адитивні технології можуть ефективно застосовуватися для виготовлення запчастин, необхідних для позапланових ремонтів машин, викликаних їх раптовими відмовами, особливо якщо простої машин із-за відмов призводять до значних виробничих втрат. Однак досі виготовлення запчастин за допомогою цих технологій не отримало великого поширення, що зумовлено рядом проблем, аналізу яких присвячена дана стаття.

У статті виконано огляд різних видів адитивних технологій, розглянуто особливості виготовлення деталей машин з металів та полімерів з їх допомогою. Обговорено причини, що стримують широке застосування адитивних технологій для виготовлення запчастин, у тому числі, висока вартість 3Dпринтерів і будівельних матеріалів, обмежені функціональні можливості 3D-принтерів і обмежений спектр будівельних матеріалів. Описана методологія оцінки економічної ефективності придбання запчастин, що виготовляються з застосуванням адитивних технологій, основу якої становить методика порівняльної оцінки витрат, пов'язаних з ремонтом, передбачають придбання запчастин, що виготовляються за різними варіантами з допомогою як адитивних, так і традиційних технологій. За результатами цієї оцінки приймається рішення про доцільність застосування адитивних технологій для виготовлення запчастин по одному з варіантів, для якого витрати, пов'язані з ремонтом, виявляються найменшими. Розглянуто окремі випадки прийняття такого рішення - виходячи з критеріїв мінімізації купівельної вартості запчастин і мінімізації тривалості їх виготовлення. Перший випадок має місце, коли необхідна запасна частина зазвичай поставляється не індивідуально, а в складі вузла або в комплекті з іншими запчастинами, причому покупна вартість вузла або пристрою набагато більше покупної вартості окремої запчастини, що виготовляється за допомогою адитивних технологій; другий - коли тривалість простою, пов'язаного з придбанням запчастини, що виготовляу2цється за звичайними технологіями, набагато більше тривалості простою, пов'язаного з придбанням запчастини, що виготовляється за адитивним технологій.

Ключові слова: ремонт машин, запасні деталі, адитивні технології, економічна ефрективність.

\section{Abstract \\ Problems of using additive technologies for the manufacture of spare parts for machines}

\author{
N.K. Tolochko, V.M. Sinelnikov, O.V. Sokol
}

Additive technology can be used effectively to manufacture spare parts required for unscheduled machine repairs caused by sudden machine failures, especially if machine downtime due to failures results in significant production losses. However, these technologies have not been widely used to date in the manufacture of spare parts, which is due to a number of problems that this article focuses on. 
The article reviews different types of additive technologies, considers the peculiarities of manufacturing machine parts from metals and polymers with their help. The reasons restraining wide application of additive technologies for manufacturing of spare parts, including high cost of 3D-printers and building materials, limited functionality of 3D-printers and limited spectrum of building materials are discussed. The methodology of estimation of economic efficiency of acquisition of the spare parts made with application of additive technologies which basis is made by a technique of a comparative estimation of the expenses connected with repair, assuming acquisition of the spare parts made on different variants by means of both additive, and traditional technologies is described. According to the results of this assessment, it is decided that it is expedient to use additive technologies for manufacturing of spare parts according to one of the variants, for which the costs associated with repair are the lowest. Individual cases of making such a decision - based on the criteria of minimizing the purchase price of spare parts and minimizing the duration of their manufacture - are considered. The first case occurs when the required part is usually delivered not individually, but as a part of a unit or in a set with other parts, and the purchase price of the unit or set is much higher than the purchase price of a separate part made with the help of additive technologies; the second case is when the duration of downtime associated with the purchase of a part made with conventional technologies is much longer than the duration of downtime associated with the purchase of spare parts made with additive technologies.

Keywords: machine repair, spare parts, additive technologies, economic efficiency.

\section{Бібліографічне посилання/ Bibliography citation: Harvard}

Tolochko, N. K., Sinelnikov, V. M. and Sokol, O. V. (2019) Problems of using additive technologies for the manufacture of spare parts for machines. Engineering of nature management, (3(13)), pp. 92 - 101.

Подано до редакції / Received: 02.10.2018 